\title{
Figurate erythematous lesion by Microsporum canis in immunosuppressed patient*
}

\author{
Karine Paschoal Botelho ${ }^{1}$ \\ Deborah Pereira Gonçalves ${ }^{2,3}$
}

\author{
Yuri Coelho Soares ${ }^{1}$ \\ Bárbara Lima Araújo Melo ${ }^{1}$
}

\section{DOI: http:/ / dx.doi.org/10.1590/abd1806-4841.20187094}

\begin{abstract}
Dermatophytes are fungi capable of invading keratinized tissues. Isolation of the fungus with the culture is essential to guide the treatment, because there are more resistant species like Microsporum canis. The chronic use of corticosteroids leads to the deregulation of immunity, promoting atypical manifestations of infections. Topical antifungal therapy is often insufficient, requiring systemic medications. We describe the case of a patient undergoing systemic corticosteroid therapy with a large figurate lesion who presented complete response to exclusively topical treatment.
\end{abstract}

Keywords: Immunosuppression; Mycology; Tinea

A 39-year-old female patient with systemic lupus erythematosus, on prolonged use of prednisone $40 \mathrm{mg} /$ day and hydroxychloroquine $400 \mathrm{mg} /$ day, for two months, presented with a round plaque with well-defined borders and extremely figurate center, with areas of scaling and of healthy skin of approximately $10 \mathrm{~cm}$ in diameter (Figure 1). The direct microscopic examination septate hyaline hyphae; the culture was positive with a white filamentous aspect and a yolk yellow reverse. The microculture showed fusiform macroconidia with more than six cellular divisions, confirming infection by $M$. canis (Figures 2 and 3). The patient was treated with isoconazole $1 \%$ associated to diflucortolone $1 \%$ cream for the first 10 days. For the following 20 days, she used isoconazole $1 \%$ cream alone, with a complete response to exclusively topical therapy (Figure 4).

The dermatophytes comprise 3 genera of fungi capable of invading keratinized tissues: Trichophyton, Microsporum, Epidermo-
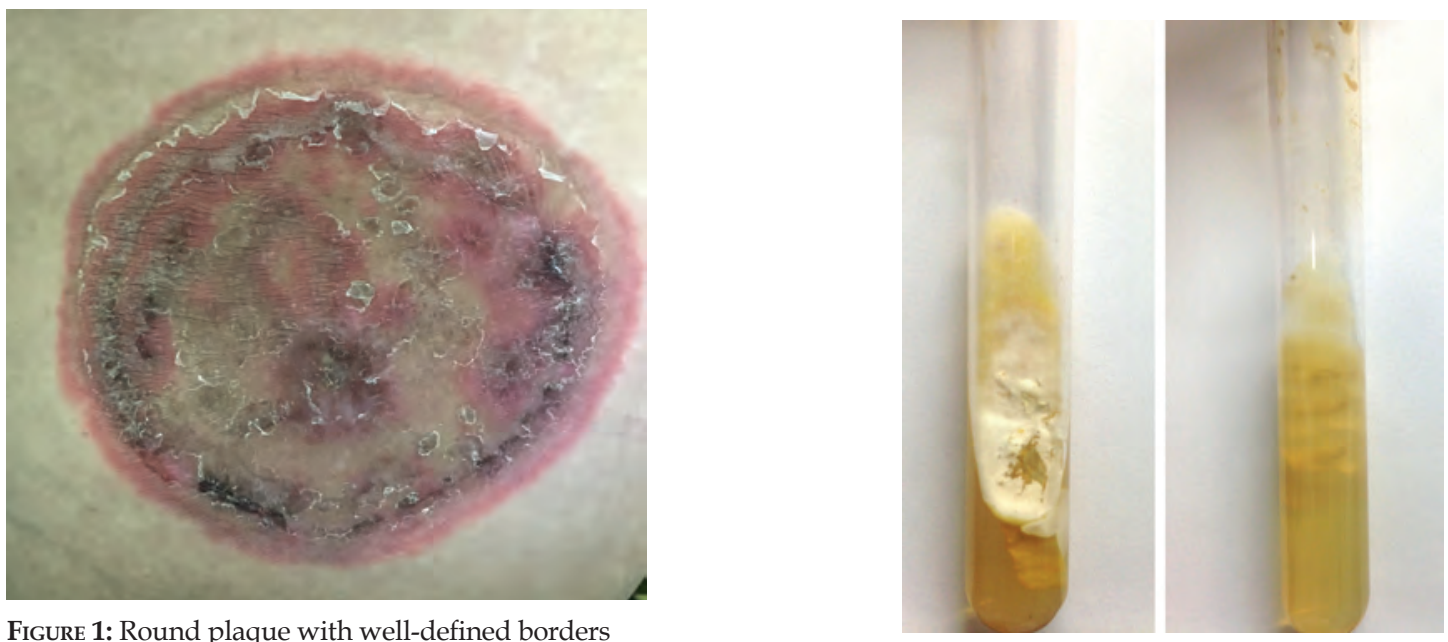

FIGURE 2: White, wooly colony with yolk-yellow reverse

\section{Received on 21.03.2017.}

Approved by the Advisory Board and accepted for publication on 20.11.2017.

* Study conducted at Centro de Dermatologia Dona Libânia - Fortaleza (CE), Brazil.

Financial support: None.

Conflict of interest: None.

\footnotetext{
Outpatient Department of General Dermatology, Centro de Dermatologia Dona Libânia - Fortaleza (CE), Brazil.

Department of Rheumatology, Hospital Universitário Walter Cantídio - Universidade Federal do Ceará (HUWC-UFC) - Fortaleza (CE), Brazil. Department of Rheumatology, Hospital Geral Dr. César Cals (HGCC) - Fortaleza (CE), Brazil.
} 


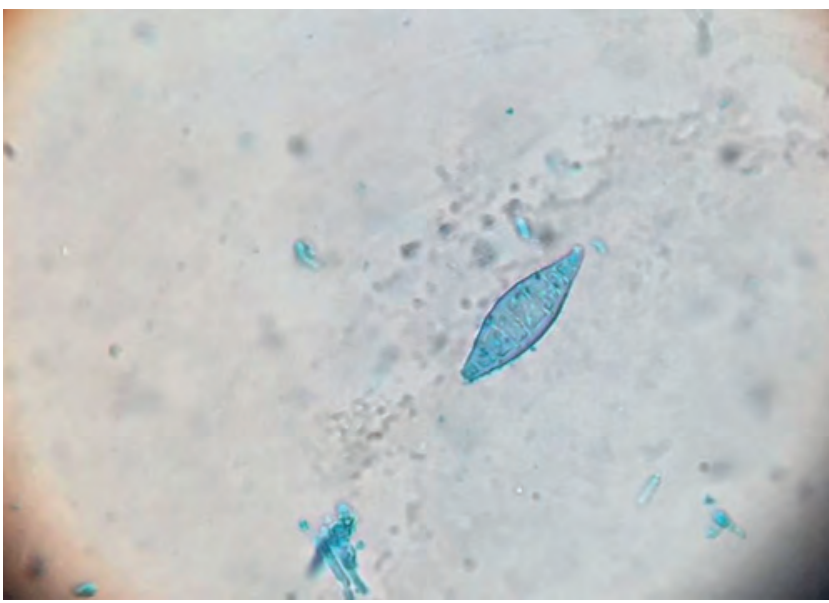

FIGURE 3: Micromorphology with fusiform macroconidia with more than 6 cellular divisions

phyton. Non-specific, cellular and humoral immunologic responses act in an attempt to block infection in the host. ${ }^{1}$

Chronic use of corticosteroids causes a deregulation mainly of cellular immunity. Its anti-inflammatory properties mask signs and symptoms of an infection, leading to atypical manifestations such as lesions that are asymptomatic, have a widespread or even figurate distribution, mimicking other conditions such as observed in this case. ${ }^{2-4}$

\section{REFERENCES}

1. Zaitz C. Dermatofitoses. In: Campbell I, Marques SA, Ruiz LRB, Framil VMS Compêndio de Micologia Médica. 2. ed. Rio de janeiro: Guanabara Koogan; 2010. p. 157-67.

2. Lionakis MS, Kontoyiannis DP.. Glucocorticoids and invasive fungal infections. Lancet. 2003;362:1828-38.

3. Peixoto I, Maquine G, Francesconi VA, Francesconi F. Dermatofitose por Tricophyton rubrum como infecção oportunista em pacientes com doença de Cushing. An Bras Dermatol. 2010;85:888-90.

4. Venkatesan P, Perfect JR, Myers SA. Evaluation and management of Funga infections in Immunocompromised patients. Dermatol Ther. 2005;18:44-57.

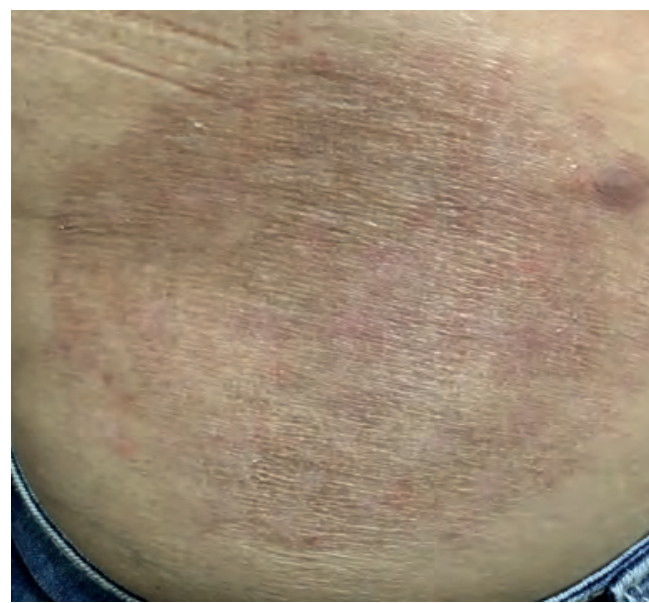

Figure 4: Lesion after treatment

Thus, immunosuppressed patients due to corticotherapy have higher risk of opportunistic infections. The isolation of the fungus in a culture is essential to guide treatment, because there are more resistant as M.canis in imunossupressed patients. ${ }^{5}$ Topical antifungal therapy alone is usually insufficient, and systemic antifungal are commonly required. ${ }^{6}$
5. King D, Cheever LW, Hood A, Horn TD, Rinaldi MG, Merz WG. Primary invasive cutaneous Microsporum canis infections in immunocompromised patients. J Clin Microbiol. 1996;34:460-2.

6. Elewski BE, Sullivan J. Dermatophytes as opportunistic pathogens. J Am Acad Dermatol. 1994;30:1021-2.

How to cite this article: Botelho KP, Soares YC, Gonçalves DP, Melo BLA. Figurate lesion by Microsporum canis in immunosuppressed patient. An Bras Dermatol. 2018;93(1):141-2. 